\title{
FAMILIAL AGGREGATION OF MUCOSAL LEISHMANIASIS IN NORTHEAST BRAZIL
}

\begin{abstract}
LÉA CASTELLUCCI,* LAY HAR CHENG, CIBELE ARAÚJO, LUIZ HENRIQUE GUIMARÃES, HÉLIO LESSA, PAULO MACHADO, MIRELA FREDERICO ALMEIDA, ADJA OLIVEIRA, ALBERT KO, WARREN D. JOHNSON, MARY E. WILSON, EDGAR M. CARVALHO, AND AMÉLIA RIBEIRO DE JESUS

Serviço de Imunologia Hospital Universitário Prof. Edgard Santos, Universidade Federal da Bahia, Salvador-Bahia, Brazil; Centro de Pesquisas Gonçalo Moniz, Fundação Oswaldo Cruz, Salvador-Bahia, Brazil; Division of International Medicine and Infectious Diseases, Weill Medical College of Cornell University, New York, New York; Departments of Internal Medicine and Microbiology, University of Iowa, Iowa City, Iowa
\end{abstract}

\begin{abstract}
To evaluate whether familial clustering occurs in mucosal leishmaniasis (ML), patients with ML (index cases) were randomly selected from medical records at a health post in an endemic area for Leishmania braziliensis infection. Control individuals (index controls) matched by age, gender, and place of residence to index cases were selected. Family members of index cases and controls were compared with respect to environmental factors and the incidence of cutaneous leishmaniasis (CL) and ML. Delayed type hypersensitivity test (DTH) to Leishmania antigen was tested in selected families. Among 289 members of 46 families enrolled, significant differences were found in the frequencies of CL (37\% versus 20\%) and ML (5\% versus 0) in case versus control families, respectively. Families with 2 cases of ML had a higher frequency $(29.6 \%)$ of DTH-positive individuals than control families $(9.4 \%)$. These data demonstrate familial clustering of CL, ML, and positive DTH skin tests in an area endemic for L. braziliensis infection.
\end{abstract}

\section{INTRODUCTION}

Leishmaniasis is a group of parasitic diseases transmitted by a sand fly vector and affecting 15 million people worldwide. Different species of Leishmania cause a spectrum of diseases. ${ }^{1}$ Leishmania braziliensis is a cause of cutaneous leishmaniasis (CL). Mucosal leishmaniasis (ML) occurs in less than $5 \%$ of patients with CL and is characterized by involvement of the nasal, oral, pharyngeal, and/or laryngeal mucosa. ML can progress to severe destructive lesions of the involved mucosal surfaces. ${ }^{2}$

The combined effect of parasite factors, host immune or genetic factors, and environmental factors may influence the outcome of leishmaniasis. ${ }^{3-5}$ Previous studies have described familial clustering of visceral leishmaniasis (VL) and CL. ${ }^{3,6,7}$ $\mathrm{ML}$ is associated with a vigorous inflammatory response to parasite antigens. ${ }^{8}$ The current study addresses the hypothesis that familial clustering of ML will also occur. To test this hypothesis, we conducted a family study to determine whether there is familial aggregation of ML in a region with a high prevalence of $L$. braziliensis infection.

\section{MATERIALS AND METHODS}

Study area. The study area surrounds the village of Corte de Pedra, located in an Atlantic forest region $280 \mathrm{~km}$ from Salvador, the capital of Bahia, Brazil. Agriculture is the basis of the local economy. The region has the highest incidence of CL of the state (316.3 per 100,000 annually; State Health Department, 1998). The population is stable with little migration out of the area. A health post established in Corte de Pedra in 1989 is a reference center for the diagnosis and treatment of leishmaniasis and serves 29 municipalities. Chagas disease and visceral leishmaniasis (Leishmania chagasi) have not been diagnosed in the area (Ministry of Health and health post records). More than $90 \%$ of the isolated parasites from lesions are L. braziliensis. Leishmania amazonensis consti-

\footnotetext{
* Address correspondence to Léa Castellucci, Serviço de Imunologia Hospital Universitário Prof. Edgard, Universidade Federal da Bahia, Salvador-Bahia, Brazil. E-mail: imuno@ufba.br
}

tutes most of the remainder. ${ }^{9}$ There are two sand fly species in this area: Lutzomia intermedia and Lutzomia withmani.

Study design. The study was a reconstructed cohort, a hybrid between a case control and a retrospective cohort study, which consists of selection of index cases and controls, and accesses the history of exposure factors and disease in all their family members, confirming the history of disease by clinical examination (presence of scar or medical records). Medical records from 1992 to 2001 from the health post of Corte de Pedra were reviewed, and 260 confirmed cases of ML were identified. The case definition of ML is a characteristic mucosal lesion with either parasitological confirmation or two of the three following criteria: positive delayed-type hypersensitivity test (DTH), positive leishmania serology, and a histopathology suggestive of leishmaniasis. All cases in the current study also responded to antileishmanial therapy.

Informed consent was obtained from the patients or parents or guardians of minors. Guidelines for human experimentation and clinical research at the authors' institution were followed. The project was approved by the ethical committee of Hospital Universitário Professor Edgard Santos in Salvador, Brazil, and the Institutional Review Boards of the Weill Medical College of Cornell University and the University of Iowa. The ethical committee of Hospital Universitário Professor Edgard Santos is registered at the National Institutes of Health USA.

Selection of case and control families. Thirty ML and 30 neighborhood control families were selected. Cases were selected randomly from 260 confirmed ML cases in clinic records in which a patient address could be identified. For each index case, an "index control" individual was identified by asking the family of the ML case about their nearest neighbors. The index control was matched by age $( \pm 5$ years if $<20$ years, \pm 10 years if $\geq 20$ years), gender, place of residence (1 $\mathrm{m}$ to $2 \mathrm{~km}$ distance from the case house), and approximately similar family size $( \pm 3)$. Index control individuals were included regardless of whether they had a history of CL or whether they were disease-free. In instances when the index control had no history of CL, at least one member of his/her family was required to have had CL to ensure that there was 
a reasonable chance of exposure to leishmania infection. The exclusion criteria for the index control were a history of ML or belonging to the same family as the ML case. First-degree blood relatives (parents, siblings, and children) of index cases ("case family cohort") were compared with those of index controls ("control family cohort"). The same degree of effort was made to interview case and control family members. Family sizes in the study averaged 7 members. Seven case families were excluded either because they refused to participate, the majority of family members was not accessible to be examined, or no control family could be found.

Case definition and evaluation of family cohorts. All participants were interviewed using a questionnaire. Information was gathered regarding the years living in the same house as the index case or control individuals, main occupation, and environmental exposures related to the risk of sand fly contact. A medical doctor examined all subjects for past or present CL and/or ML. An otolaryngology specialist confirmed all suspected cases of ML by clinical examination, nasal aspirate for Leishmania culture, and biopsy for histopathological exam. Past CL was defined as history of an ulcerated lesion of more than 3 months duration, a clinical response to therapy specific for leishmaniasis, and a typical scar confirmed by a dermatologist. If patients had been treated at the Corte de Pedra health post, the diagnosis was confirmed through medical records. Individuals without a typical history and scar were considered disease-free. Parasite cultures were performed on all new cases of CL and ML by aspiration and biopsy at the leading edge of the lesion. Parasites were cultured in blood-agar media (NNN media) enriched by Schneider's liquid media.

To compare the exposure rates of the case and control family cohorts, we selected 15 families for DTH skin testing to Leishmania antigen. Five families with 2 cases of ML, 5 families with only 1 case of ML, and 5 control families without mucosal disease were randomly selected. Leishmania skin testing was performed on these family members with $25 \mu \mathrm{g}$ of soluble L. amazonensis antigen (Brazilian Ministry of Health standard antigen) in $0.1 \mathrm{~mL}$ administered intradermally in the forearm. The DTH was considered positive if there was an induration $>5 \mathrm{~mm}$ at the site of inoculation 48 hours after intradermal inoculation.

Statistical analyses. Analyses were performed using EpiInfo 6.04c (CDC, Atlanta, GA) and SAS 6.12 (SAS Institute Inc., Cary, NC). Univariate logistic regression analysis was used to compare dichotomous variables using Fisher exact test and Student's $t$ test to compare the continuous variables between the case and control cohorts. To calculate incidence densities for CL and ML, person-years of risk was defined as the sum of "at risk" years (years living in the endemic area at disease onset or total years living in the area at interview if disease-free). Differences in the size of the DTH reaction between the subjects with disease (CL and ML) were calculated by Mann-Whitney test. In individuals without history of disease, odds ratios and exact $95 \%$ confidence intervals were calculated to evaluate the association between positive DTH and belonging to a family with 2 cases of ML, 1 case of ML, or a control family.

\section{RESULTS}

Description of case and control family cohorts. A total of 46 families were enrolled in this study: 23 case families and 23 control families. The demography, frequency of environmental variables, and history of leishmaniasis in each cohort group are shown in Table 1 . The case family and control family cohorts had similar demographics, including age, number of siblings and children, duration of residence in the house of the index case or control individuals, and the main occupation. The environmental exposures surveyed were also similar between the two family cohorts.

Frequency of past or present ML and $C L$ in the case and control family cohorts. There were significant differences between the frequencies of CL and ML in each group. Among the 150 people in the case family cohort, there were 54 individuals with confirmed CL (36\%) and 7 individuals with confirmed ML (5\%), using the case definitions defined above. Among the 139 individuals in the control family cohort, there were 27 with confirmed CL (19\%) and no individuals with confirmed ML. Of the 7 individuals discovered to have ML through this study, 3 had scars and were confirmed by medical records but were not previously on the list of the $260 \mathrm{ML}$ cases. The other 4 cases had active lesions confirmed by an otolaryngologist, a positive DTH skin test, and a lesion biopsy positive for Leishmania. One of the 4 new ML lesions cultured was positive for Leishmania.

The case family cohort had significantly increased risk of acquiring ML compared with the control family cohort [risk ratio $=1.87 ; 95 \%$ confidence interval $(1.15,3.12), P=0.016$, Fisher exact test], as well as significantly increased risk of acquiring CL [risk ratio $=1.96 ; 95 \%$ confidence interval $(1.24,3.11), P=0.015$, Fisher exact test].

DTH skin test reactivity to Leishmania antigen in selected families. DTH skin tests were positive in all patients with past CL $(N=45)$ or ML $(N=15)$, with no significant differences in the size of reaction between ML and CL patients (mean $\pm \mathrm{SD}, 25 \pm 12.3 \mathrm{~mm}$ versus $23 \pm 9.04 \mathrm{~mm}$, respectively, $P>0.05$, Mann-Whitney test). To compare the exposure rates of case and control family cohorts, cases of CL and ML were excluded from analysis of DTH reactivity. The frequency of positive DTH was compared in 92 subjects without a history of leishmaniasis across the three family cohorts (Table 2). Fifteen of the 92 individuals had positive DTH skin tests. The families with 2 cases of ML had a higher frequency of DTHpositive individuals $(30 \%)$ than either the families with 1 case of ML (12\%) or control families (9.4\%). Disease-free individuals that were members of families with 2 ML cases were more likely to have positive DTH responses than those from control families (OR 4.07; $P=0.048$ ).

The family distribution of ML, CL, and DTH-positive individuals across the families with more than $1 \mathrm{ML}$ case shows a vertical distribution of ML (from parent to child), although the data is too preliminary to draw any conclusion. Figure 1 exemplifies the pedigrees of two families.

\section{DISCUSSION}

We documented a familial aggregation of CL and ML in a region where L. braziliensis is endemic. This could be due to shared environmental and/or genetic factors influencing the clinical outcome of L. braziliensis infection. In addition, a higher frequency of DTH-positive skin test was observed in family members of ML cases without evidence of disease according to history or clinical examination. This could reflect a 
TABLE 1

Comparison of case family cohort with control family cohort: demograhics, environmental factors, and disease history

\begin{tabular}{|c|c|c|c|}
\hline \multirow[b]{3}{*}{ Number of families } & Case family cohort & Control family cohort & \multirow[b]{2}{*}{$P$ value* } \\
\hline & \multicolumn{2}{|c|}{ Number and/or percentage of total subjects } & \\
\hline & 23 & 23 & NS \\
\hline Number of persons & 150 & 139 & NS \\
\hline Mean age (years) $\pm S D$ & $26.2 \pm 16.7$ & $25.8 \pm 16.5$ & NS \\
\hline Male gender & $54 \%(81)$ & $44 \%(61)$ & NS \\
\hline \multicolumn{4}{|l|}{ Relationship to index case or control individual } \\
\hline Parent & $13 \%(20)$ & $12 \%(17)$ & NS \\
\hline Sibling & $43 \%(65)$ & $45 \%(63)$ & NS \\
\hline Child & $44 \%(66)$ & $42 \%(58)$ & NS \\
\hline Years lived in the same house as the index case/control (mean $\pm \mathrm{SD}$ ) & $22.6 \pm 14.7$ & $21.1 \pm 15.7$ & NS \\
\hline Electricity in the home & $44 \%(66)$ & $50 \%(70)$ & NS \\
\hline \multicolumn{4}{|l|}{ Occupation } \\
\hline Farm & $45 \%(68)$ & $40 \%(56)$ & NS \\
\hline Domestic & $10 \%(15)$ & $7 \%(10)$ & NS \\
\hline Student/child & $38 \%(57)$ & $42 \%(58)$ & NS \\
\hline Other & $6 \%(9)$ & $11 \%(15)$ & NS \\
\hline \multicolumn{4}{|l|}{ Risk exposures } \\
\hline Farm exposure & $92 \%(138)$ & $89 \%(124)$ & NS \\
\hline Hunting at night & $27 \%(41)$ & $17 \%(24)$ & NS \\
\hline Animals in home environment & $90 \%(135)$ & $86 \%(120)$ & NS \\
\hline Mosquito net use & $16 \%(24)$ & $10 \%(14)$ & NS \\
\hline Chicken coop in the household environment & $52 \%(78)$ & $50 \%(70)$ & NS \\
\hline Pigsty near in the household environment & $18 \%(27)$ & $15 \%(21)$ & NS \\
\hline Stable in the household environment & $15 \%(23)$ & $10 \%(14)$ & NS \\
\hline Farm in the household environment & $88 \%(132)$ & $90 \%(125)$ & NS \\
\hline Forest at the border of household & $62 \%(93)$ & $60 \%(83)$ & NS \\
\hline \multicolumn{4}{|l|}{ Disease history } \\
\hline Confirmed CL & $36 \%(54)$ & $19 \%(27)$ & $0.005 \dagger$ \\
\hline Confirmed ML & $5 \%(7)$ & $0 \%(0)$ & $0.016+$ \\
\hline
\end{tabular}

higher rate of exposure to infection in family members of index cases and/or a propensity to develop or retain a positive skin test in these individuals. More recently, experimental data suggest that Leishmania persistence in the host influences the maintenance of immunologic response. ${ }^{10,11}$ Then, it is possible that an aggregation of ML and DTH-positive individuals in families might represent a propensity to maintein the infection that could predispors to a future development of ML.

TABLE 2

Comparison of the frequency of positive DTH skin test reactions in 92 individuals without a history of cutaneous or mucosal leishmaniasis in a subset of families from the case and control family cohorts

\begin{tabular}{|c|c|c|c|}
\hline Subgroups & $\begin{array}{l}\text { No. of DTH } \\
\text { positive skin test } \\
\text { /total individuals } \\
\text { tested* }(\%)\end{array}$ & $\mathrm{OR} \dagger$ & $\begin{array}{c}95 \% \\
\text { Confidence } \\
\text { intervalsł̦ }\end{array}$ \\
\hline $\begin{array}{l}\text { Case families with } 2 \mathrm{ML} \text { cases } \\
\text { Case families with } 1 \mathrm{ML} \text { case } \\
\text { Control families with no ML } \\
\text { cases }\end{array}$ & \multicolumn{3}{|l|}{$3 / 32(9)$} \\
\hline $\begin{array}{l}\text { OTH, delayed-type hypersensitivity; OI } \\
* \text { DTH skin test reactivity was evaluat } \\
\text { families with } 2 \text { members and } 1 \text { member wit } \\
\text { past CL }(N=45) \text { or ML }(N=15) \text { had po } \\
\text { analysis. The frequency of positive skin te } \\
\text { of CL or ML. } \\
\dagger \text { Compares case families to control fan } \\
\ddagger \text { Exact } 95 \% \text { confidence intervals are re } \\
\S P=0.048 \text {, Mantel-Haenszel } \chi^{2} \text { test. } \\
\text { II } P=0.52 \text {, Fisher's exact test. }\end{array}$ & $\begin{array}{l}\text { in } 3 \text { groups of } \\
\text { ast ML and cont } \\
\text { ve DTH skin tes } \\
\text { was compared in } \\
\text { es. } \\
\text { esented. }\end{array}$ & $\begin{array}{l}\text { nili } \\
\text { we } \\
\text { abje }\end{array}$ & $\begin{array}{l}\text { thiasis. } \\
\text { ted from case } \\
\text { y patients with } \\
\text { luded from the } \\
\text { thout a history }\end{array}$ \\
\hline
\end{tabular}

A number of factors could influence the outcome of human leishmaniasis. Environmental factors include the rate of exposure to sand flies, the number of parasites inoculated by infected sand flies, preexisting immune responses to sand fly saliva products, and variation between isolates of L. braziliensis. ${ }^{12,13}$ Although not studied in humans, the outcome of infection in BALB/c mice differs when different inocula of Leishmania major are introduced. ${ }^{14,15}$ In addition, the immunomodulatory effects of a preexisting immune response to sand fly salivary components influence infection in mice. ${ }^{13}$ Our group has previously demonstrated different biological characteristics of different $L$. amazonensis isolates during infection of both humans and BALB/c mice. ${ }^{16}$ Furthermore, polymorphisms within the L. braziliensis species have been demonstrated, including in the endemic area of Corte de Pedra, and these likely influence human disease outcome. ${ }^{17,18}$ Finally, host genetic factors influencing the immune response and clinical outcome of leishmaniasis have been documented in mice and humans. ${ }^{5,7}$ L. major causes a progressive disease with a predominant type 2 immune response in BALB/c mice, whereas the same isolate causes self-healing infection and type 1 immune response in $\mathrm{C} 57 \mathrm{BL} / 6 .{ }^{19}$ Peripheral blood mononuclear cells from ML patients produce higher levels of IFN- $\gamma$ and TNF- $\alpha$ than CL patients in response to Leishmania antigen. ${ }^{8,20,21}$ Additionally, stronger DTH reaction and high levels of TNF- $\alpha$ in sera are observed in vivo in ML patients during active disease. ${ }^{4}$

The familial clustering of CL, ML, and DTH observed in the current study could reflect a common environmental ex- 

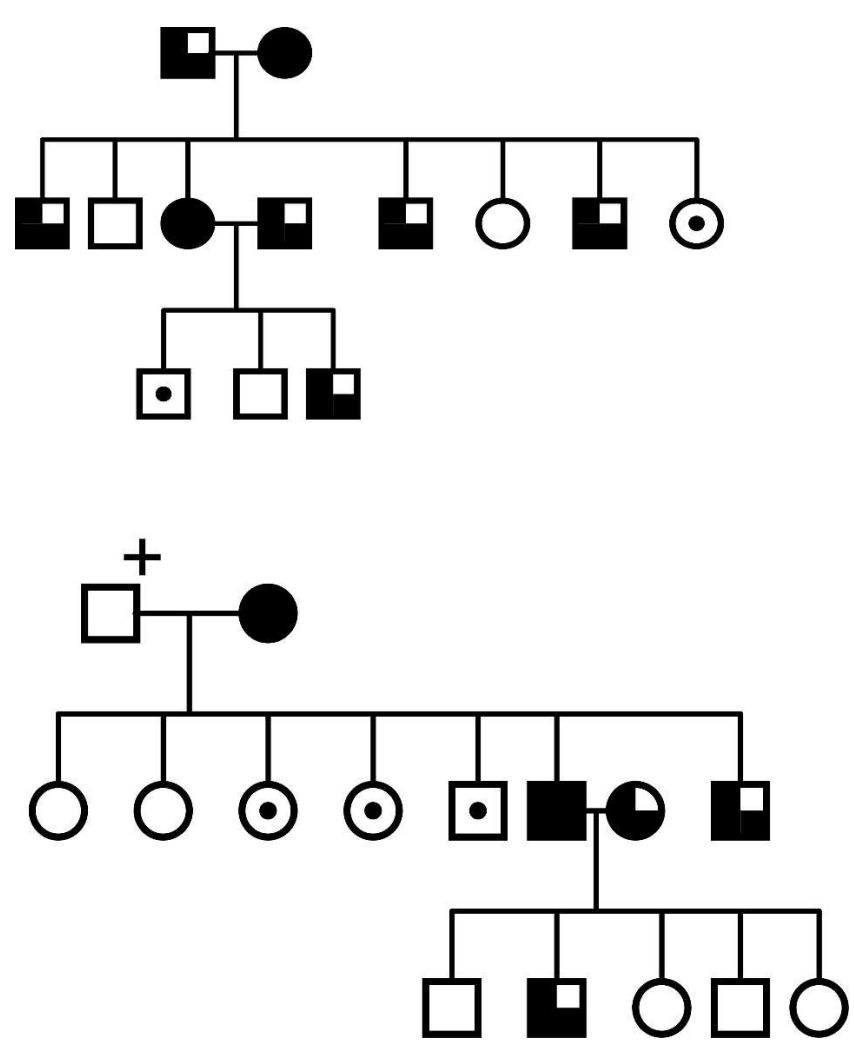

FIGURE 1. Two representative pedigrees of families with more than 1 ML case showing ML patients (ם), CL patients $(\boldsymbol{\square})$ and DTHpositive individuals without history of disease $(\square)$. All patients with past ML and CL also presented positive DTH skin tests.

posure rate. However, although both environmental and parasite factors might participate in the occurrence of CL and ML, differences in the environmental factors that we evaluated, including the years lived in the same house of the index case or control individuals, were not detected between ML and neighborhood control families. Because ML and DTH reaction both reflect a type 1 cellular infiltrate, it is also possible that familial clustering reflects a stronger reactivity to parasite antigens or parasite persistence in cases compared with control family members, manifested clinically as a higher frequency of both ML and positive DTH response. Recent data from experimental models of leishmaniasis suggest that DTH reactivity reflects parasite persistence. ${ }^{11,22}$ Moreover, genetic polymorphisms have been associated with human susceptibility to cutaneous, mucosal, and visceral leishmaniasis in other endemic areas. ${ }^{5,7,23}$ Whether the genetic backgrounds of some individuals from this region also predisposes them to develop vigorous immune responses to Leishmania antigen awaits further study of host genetic polymorphism. The distribution of CL and especially ML cases occurs from parents to siblings. However, the sample size is too small to draw any conclusions. We are accumulating more multicase families for future studies.

In conclusion, in this study we observed familial aggregation of ML and CL through a study of families of ML index cases and matched controls. It remains unclear whether the clustering is due to environmental factors influencing the manifestations of infection or to human genetic factors.

Received April 27, 2004. Accepted for publication January 13, 2005.
Acknowledgments: The authors thank Ednaldo Lago, Levy Moraes da Silva, and Maria Neuza Souza for their important work in the endemic area of leishmaniasis. We also acknowledge the physicians Roque Almeida and Albert Schriefer for their clinical support and parasite culturing in the endemic area. The authors thank students Flavia R. Esteve, Juliana Passos, Adriana A. Jesus, and Andreia B. Cruz who helped to visit the families in the endemic area. We also thank Edson Duarte and Marco A. V. Rêgo for their suggestions in study design.

Financial support: This work was supported by an International Scholars Grant from the Howard Hughes Medical Institute (EMC), by grants AI-30639-11A (P.M., W.D.J., M.E.W., A.R.J., E.M.C.) and AI048822 (M.E.W.) from the National Institutes of Health.

Authors' addresses: Léa Castellucci, Lay Har Cheng, Cibele Araújo, Luiz Henreque Guimarães, Hélio Lessa, Mirelio Frederico Almeida, Adja Oliveira, Edgar M. Carvalho, and Amélia Ribeiro de Jesus, Serviço de Imunologia Hospital Universitário Prof. Edgard Santos, Universidade Federal da Bahia, Salvador-Bahia, Brazil, Telephone: 71-237-7353, Fax: 71-245-7110, E-mail: imuno@ufba.br. Albert Ko, Centro de Pesquisas Gonçalo Moniz, Fundação Oswaldo Cruz, Salvador-Bahia, Brazil, Telephone: 71-356-4320, E-mail: aik2001@med.cornell.edu. Warren D. Johnson, Division of International Medicine and Infectious Diseases, Weill Medical College of Cornell University, New York, New York, Telephone: 212-746-6320, Fax: 212-746-8675, E-mail: wdjohnso@med.cornell.edu. Mary E. Wilson, Departments of Internal Medicine and Microbiology, University of Iowa, Iowa City, Iowa, Telephone: 319-356-3169, Fax: 319-3847208, E-mail: mary-wilson@uiowa.edu.

Reprint requests: Amelia Ribeiro de Jesus, Serviço de Imunologia, Hospital Universitário Prof. Edgard Santos, $5^{\circ}$ Andar, Rua João das Botas s/n, Canela, CEP 40110-160, Salvador-Bahia, Brazil, Telephone: 71-237-7353, Fax: 71-245-7110, E-mail: imuno@ufba.br or amelia@ufba.br.

\section{REFERENCES}

1. Desjeux P, 1992. Human leishmaniases: epidemiology and public health aspects. World Health Stat Q 45: 267-275.

2. Marsden PD, 1986. Mucosal leishmaniasis ("espundia" Escomel, 1911). Trans $R$ Soc Trop Med Hyg 80: 859-876.

3. Alcais A, Abel L, David C, Torrez ME, Flandre P, Dedet JP, 1997. Evidence for a major gene controlling susceptibility to tegumentary leishmaniasis in a recently exposed Bolivian population. Am J Hum Genet 61: 968-979.

4. Ribeiro-de-Jesus A, Almeida RP, Lessa H, Bacellar O, Carvalho EM, 1998. Cytokine profile and pathology in human leishmaniasis. Braz J Med Biol Res 31: 143-148.

5. Cabrera M, Shaw MA, Sharples C, Williams H, Castes M, Convit J, Blackwell JM, 1995. Polymorphism in tumor necrosis factor genes associated with mucocutaneous leishmaniasis. $J$ Exp Med 182: 1259-1264.

6. Jeronimo SM, Teixeira MJ, Sousa A, Thielking P, Pearson RD, Evans TG, 2000. Natural history of Leishmania (Leishmania) chagasi infection in Northeastern Brazil: long-term follow-up. Clin Infect Dis 30: 608-609.

7. Blackwell JM, Black GF, Peacock CS, Miller EN, Sibthorpe D, Gnananandha D, Shaw JJ, Silveira F, Lins-Lainson Z, Ramos F, Collins A, Shaw MA, 1997. Immunogenetics of leishmanial and mycobacterial infections: the Belem Family Study. Philos Trans R Soc London B Biol Sci 352: 1331-1345.

8. Bacellar O, Lessa H, Schriefer A, Machado P, Ribeiro de Jesus A, Dutra WO, Gollob KJ, Carvalho EM, 2002. Up-regulation of Th1-type responses in mucosal leishmaniasis patients. Infect Immun 70: 6734-6740.

9. Grimaldi G Jr, Tesh RB, McMahon-Pratt D, 1989. A review of the geographic distribution and epidemiology of leishmaniasis in the New World. Am J Trop Med Hyg 41: 687-725.

10. Belkaid Y, Piccirillo CA, Mendez S, Shevach EM, Sacks DL, 2002. CD4+CD25+ regulatory T cells control Leishmania major persistence and immunity. Nature 420: 502-507.

11. Sacks D, Noben-Trauth N, 2002. The immunology of susceptibility and resistance to Leishmania major in mice. Nat Rev Immunol 2: 845-858.

12. Grimaldi G Jr, Tesh RB, 1993. Leishmaniases of the New World: 
current concepts and implications for future research. Clin Microbiol Rev 6: 230-250.

13. Gillespie RD, Mbow ML, Titus RG, 2000. The immunomodulatory factors of bloodfeeding arthropod saliva. Parasite Immunol 22: 319-331.

14. Bretscher PA, Ogunremi O, Menon JN, 1997. Distinct immunological states in murine cutaneous leishmaniasis by immunising with different amounts of antigen: the generation of beneficial, potentially harmful, harmful and potentially extremely harmful states. Behring Inst Mitt 98: 153-159.

15. Dye C, 1992. Leishmaniasis epidemiology: the theory catches up. Parasitology 104 (Suppl): S7-18.

16. Almeida RP, Barral-Netto M, De Jesus AM, De Freitas LA, Carvalho EM, Barral A, 1996. Biological behavior of Leishmania amazonensis isolated from humans with cutaneous, mucosal, or visceral leishmaniasis in BALB/C mice. Am J Trop Med Hyg 54: 178-184.

17. Cupolillo E, Grimaldi G Jr, Momen H, 1997. Genetic diversity among Leishmania (Viannia) parasites. Ann Trop Med Parasitol 91: 617-626.

18. Schriefer A, Schriefer AL, Goes-Neto A, Guimaraes LH, Carvalho LP, Almeida RP, Machado PR, Lessa HA, de Jesus AR, Riley LW, Carvalho EM, 2004. Multiclonal Leishmania bra- ziliensis population structure and its clinical implication in a region of endemicity for American tegumentary leishmaniasis. Infect Immun 72: 508-514.

19. Coffman RL, Beebe AM, 1998. Genetic control of the T cell response to Leishmania major infection. Adv Exp Med Biol 452: 61-66.

20. Saravia NG, Valderrama L, Labrada M, Holguin AF, Navas C, Palma G, Weigle KA, 1989. The relationship of Leishmania braziliensis subspecies and immune response to disease expression in New World leishmaniasis. J Infect Dis 159: 725-735.

21. Conceicao-Silva F, Dorea RC, Pirmez C, Schubach A, Coutinho SG, 1990. Quantitative study of Leishmania braziliensis braziliensis reactive $\mathrm{T}$ cells in peripheral blood and in the lesions of patients with American mucocutaneous leishmaniasis. Clin Exp Immunol 79: 221-226.

22. Belkaid Y, 2003. The role of $\mathrm{CD} 4(+) \mathrm{CD} 25(+)$ regulatory $\mathrm{T}$ cells in Leishmania infection. Expert Opin Biol Ther 3: 875-885.

23. Karplus TM, Jeronimo SM, Chang H, Helms BK, Burns TL, Murray JC, Mitchell AA, Pugh EW, Braz RF, Bezerra FL, Wilson ME, 2002. Association between the tumor necrosis factor locus and the clinical outcome of Leishmania chagasi infection. Infect Immun 70: 6919-6925. 